\title{
Investigating Influence of Trust on Repurchasing by Mediating Role of Customer Satisfaction in Online Stores
}

\author{
Abolfazl Akhondi \& Azar Kafashpor ${ }^{2}$ \\ ${ }^{1}$ M.A. Degree of Business Administration, Ferdowsi University of Mashhad, Mashhad, Iran \\ ${ }^{2}$ Associate Professor of Ferdowsi University of Mashhad, Mashhad, Iran \\ Correspondence: Azar Kafashpor, Associate Professor of Ferdowsi University of Mashhad, Faculty of \\ Economics and Business Administration, Mashhad, Iran. Tel: 989153139423/985138805349. E-mail: \\ kafashpor@um.ac.ir
}

Received: March 10, 2016

Accepted: March 27, 2016

Online Published: April 10, 2016

doi:10.5539/mas.v10n6p126

URL: http://dx.doi.org/10.5539/mas.v10n6p126

\begin{abstract}
Analyzing and investigating factors affecting trust and satisfaction creation and providing condition for creating these factors by online stores help them to perceive customers' needs and lead to increasing loyalty level, intention for repurchasing and improving profitability level. Therefore, this paper investigates influence of trust on repurchasing by mediating role of customer satisfaction. Population of this paper were customers of online stores which have 2-star electronic trust symbol on the base of E-trade development center (Note 1) ranking and had shopping more than once. Data were gathered from 267 samples of customers by availability method and questionnaire tool and its reliability was confirmed by Cronbach's alpha with $82 \%$. Considering analyzing data by SEM on LIZERAL software, findings show that trust has positive and significant influence on repurchasing and indirect influence of trust on repurchasing by mediating role of customers satisfaction is more than its direct influence which confirms mediating role of customers' satisfaction.
\end{abstract}

Keywords: trust, E-trade, repurchasing, customer satisfaction, online stores

\section{Introduction}

Today, excessive growth of internet and consequently, expansion of electronic business causes high importance of websites and it has an undeniable role on making online relationship between companies and customers. In this regard, companies intend to expand their websites and attract more customers in initial years but in recent years, improvement of website quality and performance has get higher importance (Sohrabi and A'bedini, 2008). On the other hand, emerging internet increases customers' power. They can access products, services, brands and sellers without any limitation. Also, customers have little time and unlimited range of selection and naturally, they search for internet products which satisfy their needs and provide them with service quality. Proper usage of technology for proposing services has many potential advantages for organization including accessibility to the groups of customers. So, one of the most important issues which is raised in current competitive situation is awareness from customers satisfaction levels and their suggestions about internet products and services (Taleghani and Taghizade, 2011). On the other hand, trust in online shopping is defined as buyer's believe in moral behavior of seller which he has (Pavlou and Fygenson, 2006). In this situation, paying attention toward repurchasing as a key factor for success of online stores is considered in today competitive market. Nowadays, online stores pay attention toward repurchasing and its effective factors more than before, in this regard, this paper will test factors affecting repurchasing in online stores. By increasing growth of E-trade around the world, online stores try to get benefit from competitive advantage of more interaction with customers. Beside this, it is obvious that online shopping market is a confident way for survival in turbulent markets of today weak economy and success of online stores is depend on repurchasing. In this situation, a question raised that what make customers loyal toward one shop, what factors can provide necessary terms for customers so they repurchase from an online shop (Fang et al., 2011). Competitive advantage of internet business resulted from customer 
loyalty and his retention for repurchasing (Hellier et al., 2003, Tsai and Huang, 2007). Researches about E-trade has investigated these issues from different aspects including explanations on the base of service quality, online shopping benefits, trust and satisfaction (Gefen et al., 2003, Childers et al., 2001). Customer satisfaction is particularly important for success of online stores because it is considered as an essential incentive of delayed purchasing phenomena such as repurchasing goals (Parasuraman et al., 2005). Recognizing factors influencing repurchasing has high importance, this factor has been recognized from previous studies which is satisfaction, in fact, satisfied customer will return more likely (Lee et al., 2009). On the other hand, trusting seller is an important principle for creating loyal customer and also, keeping continuous relationship between customer and buyer (Anderson and Weitz, 1989). Many researchers argue that trust is an important factor in relationships in which there are lack of confidence, informational imbalance and affraiding from doing a job through chance such as in online shopping (Pavlou et al., 2007). Trust is a vital component in emergence and maintenance of social transactional relationships (Blau, 1964). Trust is considered as a controller mechanism that is facilitate transactional relationship which are recognized by lack of confidence, vulnerability and dependency (Bradach and Eccles, 1989). These features in online shopping environment, in which customers are unable to have individual interaction with seller, touching products physically or acquiring a product on the base of price, is seen clearly. Customers have limit information and cognitive resources and in this regard, they're looking for decreasing unreliability and complexity of online transactions by mental short paths (Grabner-Kraeuter, 2002). Because of limited control on seller and also lack of enough guarantees which state that seller will not have undesirable behaviors, trust is an important aspect of online shopping (Gefen et al., 2003). These kind of undesirable behaviors are including damaged or fake goals, deceptive explanation or using spurious pictures, inability of seller for online delivery of products and sending products which are worth less than real product. As essential term of success in economical transactions is avoiding opportunistic behaviors, generally online customers avoiding from online seller in whom, they're not trust. Considering mentioned issues, importance of cooperation in forming satisfaction and trust for creating tendency toward customer repurchasing was mentioned and lack of systematic and scientific studies about investigating influence of trust and satisfaction on repurchasing in online stores which reflects position and needs of Iran online stores, causes us to investigate influence of satisfaction and trust on providing repurchasing terms in online stores.

\section{Importance of Research}

Today, websites are connectors between companies and consumers and user perception affected by his/her experience related to the website (Wang,2008). In competitive environment, the most important factor for creating sustainable competitive advantage, is providing the best possible service and quality which lead to customer satisfaction improvement, customer retention and organization profitability. On the other hand, with increasing growth of global E-trade development, companies try to interact with customers by E-trade more and more and get competitive advantage (Taghva et al., 2008). Organizing and monitoring these internet shops is one of the necessary index for developing E-trade in Iran in a way that electronic receipt and payment system for proposing product should done in secure environment properly. One of important index on E-trade development is electronic trust. This index, increases electronic readiness of Iran and whatever it will expanded, it will causes more economical growth of Iran in global level. But what matter for these shops and is vital for continuing their activity, is investigating effective factors on customers tendency toward repurchasing from online stores. In this condition, many online stores which are active in Iran, have many problems in creating trust and enough satisfaction in customers. Undoubtedly, analyzing effective factors on creating trust and satisfaction and providing terms of these factors creation help these shops so much to satisfy customers demands in the best way and causes increasing loyalty level and tendency for customers repurchasing and online shopping, therefore, by using this method, in addition to the saving time, buyer selects and buys his/her intended product easily and receive it at his/her home without any problem, also all steps of buying, selling and selecting product, delivering and receiving, financial transactions etc. could be done electronic as fast as possible. On the other hand, intention for repurchasing is an important factor in future relationship of customer with organization, its profitability and as a result, business success of that organization. Accordingly, necessities of doing such research is obvious, so this research aims to investigate this gap in online stores.

\section{Literature Review}

\subsection{Investigating Relationship between Customers Satisfaction and Trust}

Customers' satisfaction measures quality of relationship between satisfied customers and considered organization. Also, satisfied customer improves loyalty level of people toward organization, it means that customers loyalty help formation of valuable relationships foundations with a company. Satisfied customers often will purchase and express their positive trade with organization through their communication. Adjusting 
customers expectations with organizational performance and making customers who are powerful in making added value for organization, has high importance. Satisfaction has made when customer receive his/her mentioned services completely and being sure that supplier provided him/her with services in suitable time and place and take a little risk. Satisfaction is effective on customer decision about keeping his/her relationship with organization and decreasing possibility of leaving organization by customer side. Relationships in which customer has positive trust and experience toward system, causes decreasing in perceived risk of customer. Trust develops when there is high degree of confidence toward trust ability and integration of company. For acquiring trust, organization strategy should paying attention toward effective interactions and being adaptable with customers norms and it is tried to avoid negative reputation of company in public opinion. So, communication can have considerable influence on customers trust and satisfaction degree, as it can transfer information between customers and organization. Researches show that communication as a powerful aspect of trust, can preserve customers trust toward different systems. Satisfaction is one of important basis of trust and in some areas, could be introduced as a company ability for developing behavioral norms and revealing trust (Landua, 2008). So, it is expected that trust has a positive and significant effect on customers satisfaction in online stores.

\subsection{Investigating Relationship Between Trust and Repurchasing}

While customers satisfaction is recognized as an important factor, this variable is just one of the variables influencing repurchasing behavior of customers. There are many researchers which have paid attention toward influence of trust and satisfaction on repurchasing behavior (Chow \& Holden, 2002). When customers trust service providers, probably become loyal toward those service providers (Deng et al., 2010). One of factors challenge this relationship seriously, is related to the changes of business environment, as by moving to E-trade and using these kind of services more by customers, set of factors such as usage simplicity, perceived security and perceived profitability finally lead to improving customers trust toward online service usage. When customers has a good experience from this relationship and high satisfaction from his/her shopping, finally it could be expected that customer will repurchase through internet systems by E- trade portal (Chiu, 2012). So it is expected that trust has positive and significant influence on repurchasing through online stores.

\subsection{Investigating Relationship Between Satisfaction and Repurchasing}

Consumer shopping behavior always considered as an important issue for managers (Cheng, 2012). So, for both business professionals and academician who are interested in recognizing tendencies toward repurchasing among customers, satisfaction is one of important aspect of attracting customers and their retention for organization. Many organizations try to attract customers for repeating shopping behavior, so by increasing service quality level, they can improve people satisfaction level and finally, catch their goal by repeating intended behavior (Wei, 2006). It should be said that customers satisfaction and service quality are key areas for one organization. In fact, when customers can buy products of a company by which, feel high profitability, then after purchasing them become satisfied(Arshad, 2014). In related research of satisfaction field, it is stated that this index has a direct relationship with repurchasing tendency of customer (Mittal \& Kamakura, 2001). Relationship between customers satisfaction and behavioral tendency had been confirmed by many studies in two areas of services and products (Fullerton, 2005). Davis-Esramek et al., suggest that relationship between satisfaction and behavioral loyalty is not linear and has two levels of critical threshold. When satisfaction decreases below the lower threshold (region of escape) shopping behavior decreases fast. Between threshold levels (reflection region) shopping behavior is constant. They believe that satisfaction should be high enough to motivate behavioral loyalty or be low enough to decrease it. So it is expected that customers satisfaction has a positive and significant influence on repurchasing in online stores. Considering suggested hypotheses, research model extracted from Fang et al. (2011) research, types of justice and quality variables were removed and trust variable mentioned as a dependent variable, now in this article it is considered as an independent variable. So, by considering adapted model, researcher will investigate influence of trust on repurchasing by mediating role of customer satisfaction. 


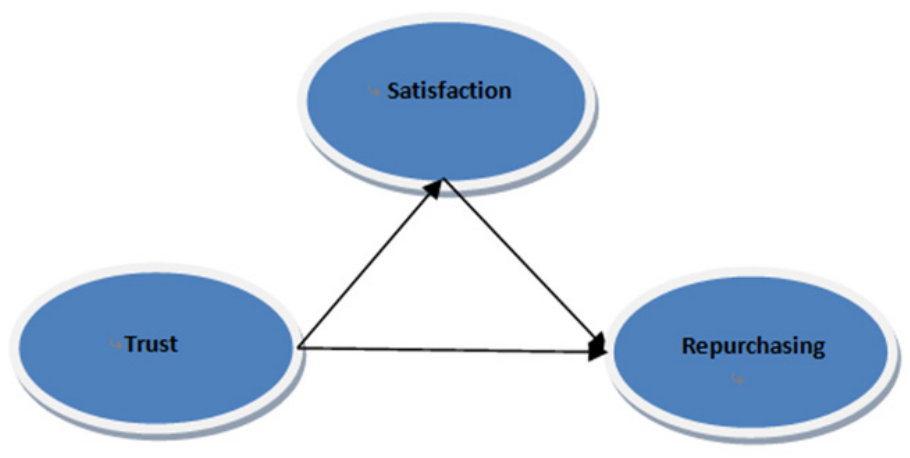

Cognitive model of research (adapted from Fang et al., 2011).

\section{Research Methodology}

As this research aims to describe investigated condition and phenomena for more recognition of current condition and helps to decision making process, so this research could be considered as a descriptive research on the base of gathering data method and as it is investigate relationship between variables, it is correlative type. Considering subject and hypothesis, this research is applicable due to its goal and it is survey one by its method. In this study, researcher used questionnaire for gathering data. For measuring trust (independent variable), satisfaction (intervening variable) and repurchasing variables (dependent variable), questionnaire of Fang et al. (2011) and shin et al. (2013) articles was used. Population of this research were customers who used one of the active online stores services in Iran more than once. on the other hand, for recognizing authentic online stores, a referee named Electronic Trust symbol which is active under supervision of Ministry of industry, mine and trade, was used and among 3380 online stores registered on this referee website, only 165 websites were successful to receive 2-star trust symbol which is the highest degree of trust .In this research, online shop which have 2-star trust symbol were considered. As sampling method was non-probability, for this research out criterion was availability and cooperation of online stores, then by considering that criterion, 4online stores cooperate with us. Because there was not available list for online stores customers, we just can distribute questionnaire among their customers. Judgmental sampling was used. For unlimited population of this research, 267 samples were determined by Cochran formula and questionnaires were distributed among customers who had shopping more than once. SEM was used for testing hypotheses and fitting model. For testing hypotheses, probability value of (t-value) resulted from model fitting was used for significance parameters. As considered confidence degree is $95 \%$, significant value on $95 \%$ degree is 1.96 , so values between $(1.96,-1.96)$ range, are not accepted and values out of this range are acceptable. Criteria used in this research are as follow:

Relative Chi- square $\left(\chi^{2} / \mathrm{df}\right)$ : one of the common criteria for taking free parameters into account on calculating fitting criterion is relative Chi-square which is calculated by easily dividing Chi-square value on model degree of freedom and its acceptance value is between 1 and 3 .

Root mean square error of approximation: it is calculated square of approximated error variance which is reported decimal. This criterion could be calculated for different confidence intervals and acceptable models have value below 0.1 . models fitting which have values more than 0.1 , are calculated weakly.

Comparative fitting index: this index tests important values through independent model in there's no relationship among variables and suggested model. Researchers believe that acceptable values for this index are which more than 0.9 .

Goodness of fit index: this index, calculates all defined squares relative to the all calculated matrix squares by model. its variation is between 0 and 1. Its acceptable value should be more than 0.9.

Normed fit index: It is one of the normed indexes. This index is on the base of correlation between existed variables of model as high coefficients among them resulted in high values of normed fit index. Its acceptable value should be more than 0.9 .

Root mean square residual: it is an index for measuring average residual. In model which has a fitting goodness, these residual are too little and more this index close to zero, more better will be the model fitting.

\section{Research Findings}

After distributing 30 questionnaires, as initial sample, Qronbach's alpha value was calculated by all 16 items of 
questionnaire and also, reliability results of each index are given in table 1. Because Qronbach's alpha is more than 0.7 in all variables of questionnaire, it could be said that questionnaire has good reliability.

Table 1. Questionnaire reliability results

\begin{tabular}{lll}
\hline Qronbach's alpha & Number of questions & Variables \\
\hline 0.767 & 7 & Trust \\
0.847 & 5 & Satisfaction \\
0.862 & 4 & Repurchasing \\
\hline
\end{tabular}

After verifying questionnaire validity, it is time to implement it, so in this research, questionnaires should be distributed online among customers of online stores and term of filling out this questionnaire will be shopping more than once. By using Kolmogorov-Smirnov, data normal distribution was investigated. This test was used for investigating normality of questionnaire variables so if this term being applied, maximum likelihood method could be used in SEM. Test results are given in table2.

Table 2. Kolmogorov-Smirnov test results statistics

\begin{tabular}{llll}
\hline Significance level & Test & Number of data & Variables \\
\hline 0.548 & 2.776 & 267 & Trust \\
0.876 & 3.811 & 267 & Satisfaction \\
0.182 & 2.831 & 267 & Repurchasing \\
\hline
\end{tabular}

As significant degree of this test which is related to the all variables, is higher than 0.05 , normality of research variables is accepted and likelihood ratio test could be used in SEM. The most important stage of statistical analyze in SEM is investigating data model fitting, in this case, confirmatory factor analysis will be used. In fact, confirmatory factor analysis is one of the most important aspect of SEM in which, given hypotheses are tested for loadings factor structure and mutual correlations among variables. As mentioned before, SEM has two sections of measuring model and structural model, confirmatory factor analysis measures section of SEM which is calculated by LIZERAL software. In this research, investigating questionnaire validity and also finding out those items which are defining considered factors, confirmatory factor analysis was used by using LIZERAL $8 / 80$ software. Confirmatory factor analysis is used for evaluating validity of measurement scale. This model is base on pre-experimental information about data structures and before path analysis (Structural models), at first, confirmatory factor analysis (measurement model) should be done and it is investigated whether selected questions provide suitable factor structures and necessary studied aspects of research model. In confirmatory factor analysis, if factor loadings value be lower than 0.3, considered little and should be removed from model and also if t-value be more than 1.96 or lower than -1.96 , indexes provide suitable factor structures. For measuring studied aspects of research model in 0.95 confidence level. Confirmatory factor analysis results are given in table 3.

Table 3. Results of variables Confirmatory factor analysis

\begin{tabular}{lllll}
\hline Standard Error (SE) & T statistic & Factor loadings & Question number & Variables \\
\hline 0.022 & 17.23 & 0.8 & SA1 & Satisfaction \\
0.040 & 20.57 & 0.83 & SA2 & \\
0.039 & 21.27 & 0.82 & SA3 & \\
0.043 & 17.66 & 0.76 & SA4 & \\
0.036 & 21.54 & 0.77 & SA5 & \\
0.015 & 21.27 & 0.85 & RI1 & Repurchasing \\
0.034 & 22.36 & 0.76 & RI2 & \\
0.052 & 17.93 & 0.93 & RI3 & \\
0.062 & 15.14 & 0.94 & RI4 & Trust \\
0.042 & 15.18 & 0.64 & TR1 & \\
0.065 & 9.69 & 0.63 & TR2 & \\
0.049 & 12.11 & 0.59 & TR3 & \\
0.039 & 17.23 & 0.67 & TR4 & \\
\hline
\end{tabular}




\begin{tabular}{llll}
\hline 0.044 & 10.58 & 0.47 & TR5 \\
0.051 & 12.68 & 0.65 & TR6 \\
0.045 & 11.87 & 0.53 & TR7 \\
\hline
\end{tabular}

On the base of table 3, t-value is more than 1.96 in all items and also, factor loadings is more than 0.3 , so it could be concluded that selected questions provide suitable factor structures for measuring studied aspects. Also, fit indexes of model confirm these results which are given in table4.

Table 4. Fitting indexes

\begin{tabular}{lllc}
\hline Resulted value & Acceptable values & Description & Test name \\
\hline 2.14 & $3<$ & Relative Chi- square $\left(\chi^{2} / \mathrm{df}\right)$ & $\chi 2 / \mathrm{df}$ \\
0.065 & $1<\mathbf{0 /}$ & Root mean square error of approximation & RMSEA \\
0.92 & $9>\mathbf{0} /$ & Goodness of fit index & GFI \\
0.033 & $1<\mathbf{0 /}$ & Root mean square residual & RMR \\
0.98 & $9>\mathbf{0} /$ & Normed fit index & NFI \\
0.99 & $9>\mathbf{0} /$ & Comparative fitting index & CFI \\
\hline
\end{tabular}

Considering table 4, RMSEA value is 0.065 and as it is lower than 0.1 , it shows that errors square average of model is suitable and model is acceptable. Also, Chi 2 value in comparison with degree of freedom is between 1 and 3 and also the amount of GFI, CFI and NFI is more than 0.9 which shows that measurement model of research variables is a suitable model. Considering confirmation of questions related to the questionnaire aspects (questionnaire validity), in next section we will test hypotheses and investigating them by confirmed aspects of fitted model in graphs 1 and 2.

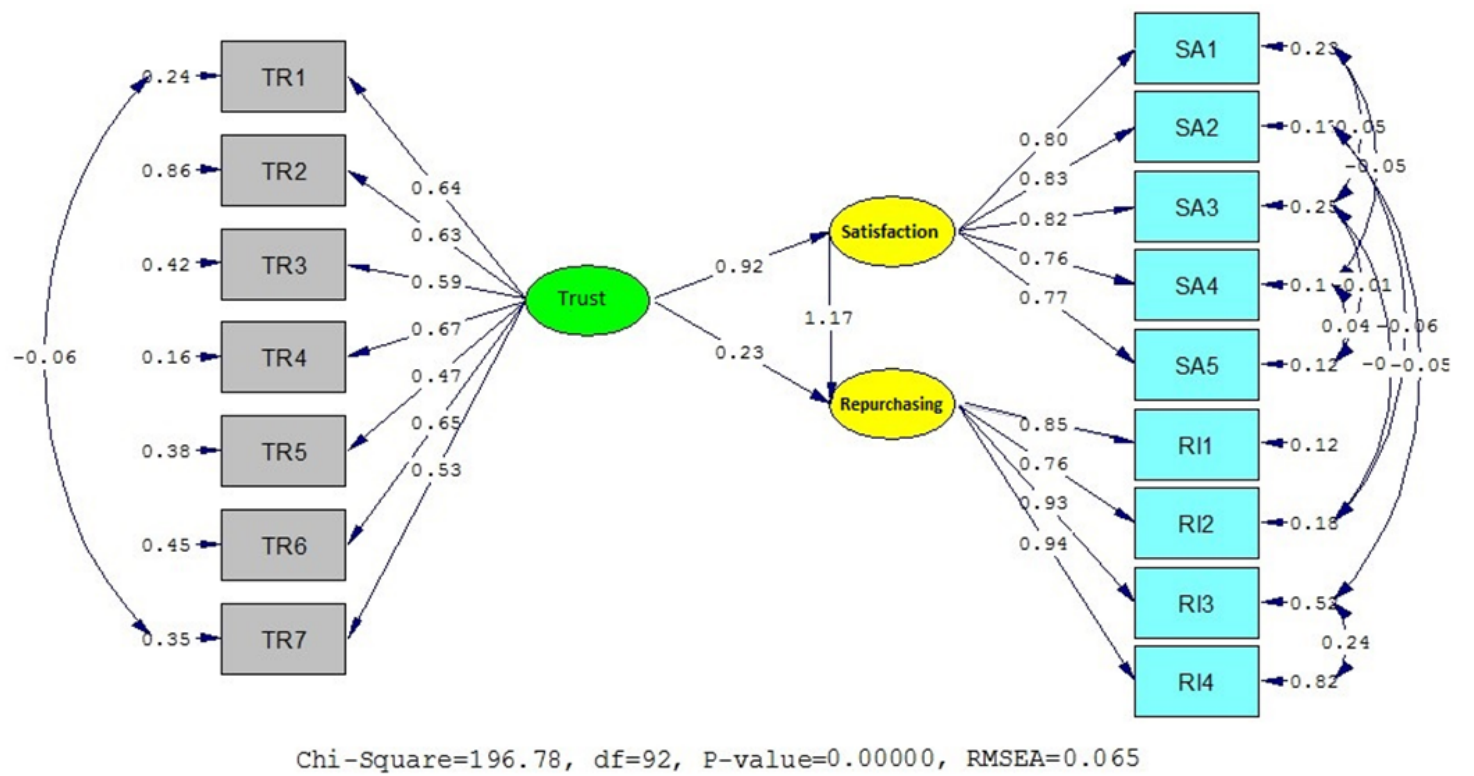

Figure 1. factor coefficients and path coefficient of research model 


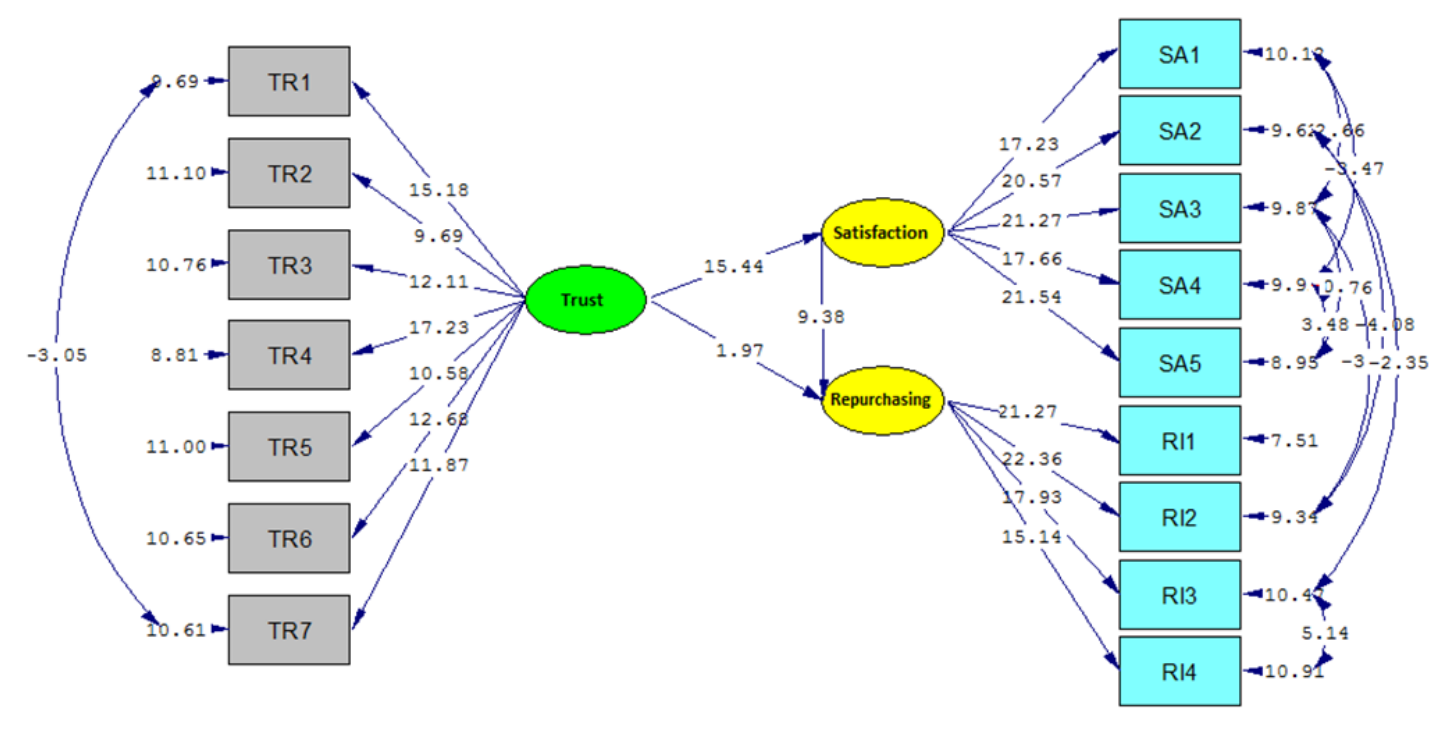

Chi-Square=196.78, df=92, P-value=0.00000, RMSEA=0.065

Figure 2. significance of resulted coefficients by $\mathrm{T}$ test of model

\section{Conclusion}

General questions results which are related to the respondents features show that $95.9 \%$ of respondents were men and $4.1 \%$ were women. Due to the education, $49.4 \%$ of respondents had B.A degree. Also it could be said that most of customers are young people as most frequency related to the people aged between 21 to 30. Important point should be considered was low tendency of women for shopping from online stores which could be investigated from different aspects such as women tendency for physical (tangible) shopping and purchasing culture of Iranian women. On the base of graph 1, amount of path coefficient between customers trust and satisfaction is equal to 0.92 which is a positive amount. On the base of graph2, t-value is equal to 15.44 which is more than 1.96, so by $95 \%$ confidence it could be said that there is a positive and significant relationship between customers trust and satisfaction and first hypothesis of research being accepted. In first hypothesis, it is determined that trust has positive and significant influence on satisfaction in online stores. This hypothesis results are agree with Fang et al. (2011) and Pappas et al. (2014) results, so by increasing trust on online stores, customers satisfaction will improve. Investigating second hypothesis shows that trust has positive and significant influence on repurchasing. On the base of resulted graph, the path coefficient between customers trust and repurchasing is equal to 0.23 which is a positive amount. T-value is equal to 1.97 which is more than 1.96 , so by 95\% confidence it could be said that there's a positive and direct relationship between customers trust and repurchasing and second hypothesis is accepted. This result is agree with results of Aren et al. (2013), Fang et al. (2011) and Shin et al. (2013) researches. In third hypothesis and on the base of resulted graph, the path coefficient between customers satisfaction and repurchasing is equal to 1.17 which is a positive amount. T-value is 9.38 which is more than 1.96 , so by $95 \%$ confidence, it could be said that there is a positive and significant relationship between customers satisfaction and repurchasing and third hypothesis is accepted. Ghasemi Shoorjeh (2012), Fang et al. (2011), Poor mostafa Khoshkroodi et al. (2013) and Hadadian et al. (2012) also investigate influence of customers satisfaction on repurchasing and their results are agree with this research result but it is not agree with Shin et al. (2013) conclusion as they show that satisfaction has not positive influence on repurchasing. As a main goal of research, the mediating role of customer satisfaction between influence of trust and customer repurchasing was investigated and indirect influence of trust on repurchasing was analyzed. As first and third subsidiary hypotheses were accepted, so indirect influence of trust on repurchasing is significant. Considering research result and second subsidiary hypothesis in which, path coefficient is equal to 0.23 , it could be said that indirect influence of trust on repurchasing is more than direct influence, so we can conclude that customer satisfaction has mediating role between trust and repurchasing. So, our result is agree with Fang et al. (2011) result. As there is a significant relationship between customer trust and satisfaction, strategies for increasing customers trust which will be resulted in their satisfaction, should be mentioned along with this issue, ministry of industry, mine and trade steps forward, determines valid shops and ranks them so shops owners can put this ranking on their websites. So, first step for creating trust in buyers who refer to the online shop for the first time, had been taken. On the other hand, providing secure payment system can increase 
customers trust, so it is proposed to use bank transactions with high security so it can prevent hackers from entering into the system. Also, considering security policies, shop users should ensure that their information will be kept by shop secretly and they will not use it for commercial goals, so when customers use shop website, perceive risk as little as possible. On the other hand, tracking unsuccessful transactions while customers purchase something, lead to perceived risk decreasing and lack of trust by customers. Additionally, it is necessary to announce security messages by online shop for making customers aware. Also, it is recommended to devise a system for tracking delivered package, so by its number, customer become aware about procedure of delivery package by post office. This system as a "tracking postal items" currently exists in which by entering delivered item number, its final situation become specified, online stores can increase customers satisfaction and trust by devising such system and linking this system to the tracking web page and making customer aware about delivered package situation. Considering importance of satisfaction and its influence on repurchasing and as there is no real space on websites for asking questions about products and services, it is suggested to provide more facilities for more interaction with customer. On the other hand, results show that Iranian women have lower tendency for online shopping and its reason can be related to the shopping culture of Iranian women who want to see their interesting products closely, so we should provide them with condition in which, they can make better relationship with products for online stores by 3D photos and more photos from different views and also pinpointing products size such as in clothes, can motivate women for shopping. Also, possibility of writing comment for customers should be provided so that customers who want to buy something, can expire easier shopping by reviewing other buyers comments. Also, informing others by mass media, sending customers e-mail and making them aware about products and new terms, lead to increasing customers satisfaction and repurchasing from shop. Considering results about relationship between trust and repurchasing by mediating role of customer satisfaction in a way that influence of trust on repurchasing is lower than indirect influence of trust by mediating role of satisfaction, this issue should be mentioned that this research basis for gathering information were customers who had shopping from online stores more than once. So, results show that customer trust is a main factor for the first shopping, it means when customer make shopping by considering factors which are provided to make him/her trust, and receive his/her product, he trust online shop but for repurchasing, as customer had shopping in the past and make shopping from shop again, this action reason is a satisfaction that he had from product bought in the past and have satisfaction, considered an important factor for continuing shopping by customer. So it is recommended that shops paying more attention toward customers satisfaction and considering factors which cause its improvement, in a way that make a facility for online and offline communications with customers. On the other hand, by managing and analyzing customers comments and applying them by online shop, can make customers more satisfied. Also, satisfied customers are identified so they can make a plan to continue communication with customers. Also, scoring system with some rewards has been considered for customers who have continuous shopping, so by gathering enough scores, they can receive rewards or shop consider Ben Deals per shopping so make them more satisfied with repurchasing.

\section{References}

Anderson, E., \& Weitz, B. A. (1989). Determinants of continuity in conventional industrial channel dyads. Marketing Science, 8(4), 310-23.

Aren, S. G. M., Kabaday, E., \& Alpkan, L. (2013). Factors Affecting Repurchase Intention to Shop at the Same Website. Procedia Social and Behavioral Sciences, 99(9), 536-544.

Arshad, R. (2014). Perceived Service Quality and Customer Satisfaction with Mediating Effect of Purchase Intention. Academy of Contemporary Research Journal, 8(2), 40-49.

Blau, P. M. (1964). Exchange and Power in Social Life, John Wiley and Sons, New York, NY.

Bradach, J. L., \& Eccles, R. G. (1989). Price, authority, and trust: from ideal types to plural forms. Annual Review of Sociology, 15(1), 97-118.

Cheng, C. C., Chiu, S. I., Hu, H. Y., \& Chang, Y. Y. (2011). A study on Exploring the Relationship between Customer and Loyalty in the Fast Food Industry: With Relationship Inertia as a Mediator. African Journal of Business Management, 5(13), 5118-5126.

Childers, T. L. Carr, C. L. Peck, J., \& Carson, S. (2001). Hedonic and utilitarian motivations for online shopping behavior. Journal of Retailing, 77(4), 511-35.

Chiu, C. M. (2012). Re-examining the influence of trust on online repeat purchase intention: The moderating role of habit and its antecedents. Decision Support Systems, 53(4), 835-845.

Chow, S., \& Holden, R. (2002). Toward an understanding of loyalty: The moderating role of trust. Journal of 
Managerial, 9(3), 275-299.

Davis-sramek, B., Mentzer, T. J., \& Sank, P. T. (2007). creating Consumer durable retailer Customer loyalty through order fulfillment service operations. Journal of operations management, 221-225.

Deng, Z., Lu, Y., Wei, K. K., \& Zhang, J. (2010). Understanding Customers Satisfaction and Loyalty: An empirical study of mobile Instant messages in China. International Journal of Information Management, 30(2010), 289-300.

Fang, Y. H., Chiu, C. M., \& Wang, E. T. G. (2011). Understanding customers' satisfaction and repurchase intentions: An integration of IS success model, trust, and justice. Internet Research, 21(4), 479-503.

Fullerton, G. (2005). The Impact of Brand Commitment on Loyalty to Retail Service Brands. Canadian Journal of Administrative Sciences, 22(2), 97-110.

Gefen, D., Karahanna, E., \& Straub, D. W. (2003). Trust and TAM in online shopping: an integrated model. MIS Quarterly, 27(1), 51-90.

Ghasemishoorje, M. (2012). Recognizing and analyzing customer satisfaction factor and its influence on repurchasing intention at Behpakhsh companies. M.A. thesis. Isfahan university.

Grabner-Kraeuter, S. (2002), “The role of consumers' trust in online-shopping. Journal of Business Ethics, 39(1/2), 43-50.

Hadadian, A., Sana'eei, A., Rashid, K. M., \& Ranjbaran, B. (2012) Analyzing relationship between perceived value,perceivedquality,customer satisfaction and repurchasing intention at chain stores of Tehran. Business Adminstration Journal, 11, 55-70

Hellier, P. Geursen, G. Carr,R..\& Rickard, J. (2003). "Customer repurchase intention: Ageneral structural equation model".European Journal of Marketing, 37(11/12), 1762-1800.

Hong, I. B., \& Cho, H. (2011). The Impact of Consumer Trust on Attitudinal Loyalty and Purchase Intention in B2C E-marketplace: Intermediary Trust vs Seller Trust. International Journal of Information Management, $31,469-479$.

Landua, I .(2008). Gaining Competitive Advantage through Customer Satisfaction. Trust and Confidence in Consideration of the Influence of Green, 108-117.

Mittal, V., \& Kamakura, W. A. (2001). Satisfaction, Repurchase Intent, and Repurchase Behavior: Investigating the Moderating Effect of Customer Characteristics. Journal of Marketing Research, 38(1), 131-42.

Palvia, P. (2009). The role of trust in e-trade relational exchange: a unified model. Information \& Management, 46(4), 213-220.

Pappas, I. O., Pateli, A. G., \& Giannakos, M. N. (2014). Moderating effects of online shopping experience on customer satisfaction and repurchase intentions. International Journal of Retail \& Distribution Management, 42(3), 187-204.

Parasuraman, A., Zeithaml, V. A., \& Malholtra, (2005). E-S-QUAL: A multiple-item scale for assessing electronic service quality. Journal of Service Research, 7(3), 213-35.

Pavlou, P. A., \& Fygenson, M. (2006). Understanding and predicting electronic trade adoption: an extension of the theory of planned behavior. MIS Quarterly, 30(1), 115-43.

Pavlou, P. A., Liang, H., \& Xue, Y. (2007). Understanding and mitigating uncertainty in online exchange relationships: a principal-agent perspective. MIS Quarterly, 31(1), 105-36.

Poor, M., Khoshkroodi, M., Sana'eei, A., Ghazifard, A. M., \& Nasirzade, M. A. (2013) Investigating influence of electronic services quality on customers satisfaction and repurchasing intention. Business Adminstration perspective, 12, 87-108.

Shin, J. I. K., Chung, K. H., Ohb, J. S., \& Lee, C. W. (2013). The effect of site quality on repurchase intention in Internet shopping through mediating variables: The case of university students in South Korea. International Journal of Information Management, 33(3), 453-463.

Sohrabi, B., \& A'bedin, B. (2008). Evaluating website structure using behavior modeling of visitors: A case study. Human Science Journal, 115-140.

Taghva, M. R., Taghavifard, M. T., \& Afkhami, A. (2008) Influence of website on customers satisfaction in E-trade (case study: Mellat and Iran insurances). Journal of Economy and new business, 10\&11, 58-85. 
Taleghani, M., Taghizade, M. R. (2011). Investigating relationship between service quality and customer satisfaction by emphasizing on Rust \& Oliver model. Industries engineers Journal, 14, 1-6.

Tsai, H. T., \& Huang, H. C. (2007). Determinants of e-repurchase intentions: An integrative model of quadruple retention drivers. Information \& Management, 44(3), 231-9.

Wang, L. (2008). Design and analysis on customer preformation of enterprises based on DEA technique. International conference on information management. Innovative Management and Industrial Engineering, 96-98.

Wei, M. L. (2006). A Structural Equation Model of Customer Satisfaction and Future Purchase of Mail-Order Speciality Food. Journal of Business Science and Applied Management, 1(1), 85-101.

Notes

Note 1. Under supervision of Ministry of Industry, mine and trade - Iran

\section{Copyrights}

Copyright for this article is retained by the author(s), with first publication rights granted to the journal.

This is an open-access article distributed under the terms and conditions of the Creative Commons Attribution license (http://creativecommons.org/licenses/by/3.0/). 